\title{
UCRL-ID-139582-Q3-FY03
}

II WPE NCE IUIRACAE WATIONAL LADOAATOAY
Development of a Rolling Process Design Tool for use in Improving Hot Roll Slab Recovery Quarterly Report: Q3 FY03

Dr. R. Couch, Dr. P. Wang

July 31, 2003 


\title{
Development of a Rolling Process Design Tool for Use in Improving Hot Roll Slab Recovery
}

\author{
Lawrence Livermore National Laboratory \\ Principal Investigator: Dr. Richard Couch \\ PO Box 808; L-99 \\ Livermore, CA 94550 \\ Phone: $925-422-1655$ \\ FAX: 925-422-3389 \\ couch1@1lnl.gov
}

and by

\author{
Alcoa Incorporated \\ Principal Investigator: Dr. Paul Wang \\ Alcoa Technology Center \\ ATC-B \\ 100 Technical Drive \\ Alcoa Center, PA 15069 \\ Phone:724-337-2004 \\ FAX: 724-337-2005 \\ Paul.Wang@alcoa.com
}

Quarterly Report: Q3 FY03

\section{LLNL Input}

In this quarter, an FEM simulation has been performed to compare the shape of the deformed slab after the $8^{\text {th }}$ reduction pass with the experimental metrology data provided by Alcoa Technical Center (ATC). Also, a bug in the thermal contact algorithm used in parallel processing have been identified and corrected for consistent thermal solutions between the rollers and the slab.

The overall shape of the slab at the end of the $8^{\text {th }}$ pass is shown in Figure 1. Comparison of the sectional views at the center plane along the length of the slab for both experiment and simulation, shows that the curvature at the slab mouth at the centerline is slightly higher than the experimental result as shown in Figure 2. We are currently focusing on tuning the parameter values used in the simulation and a more complete parametric study for validation is underway.

Also, unexpected fracture occurred along the surface of the slab in the $9^{\text {th }}$ pass as shown in Figure 3. We believe that the reason is due to previously noted inadequacies in the fracture model at low strain rates and high stress triaxiality. We are expecting to receive a modified fracture model based on additional experiment shortly from Alcoa. 
Validation simulations for the refined fracture model will be performed when the model becomes available.

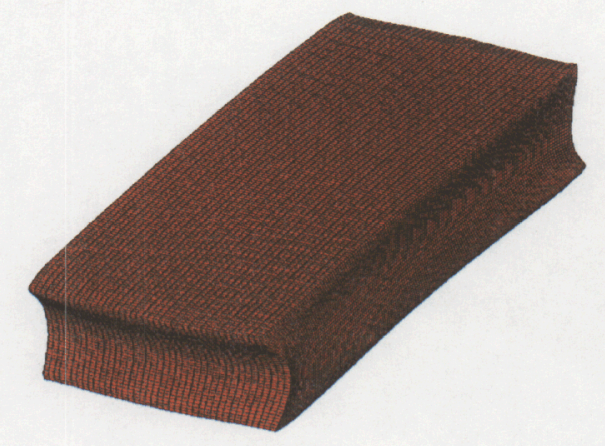

a) Experiment

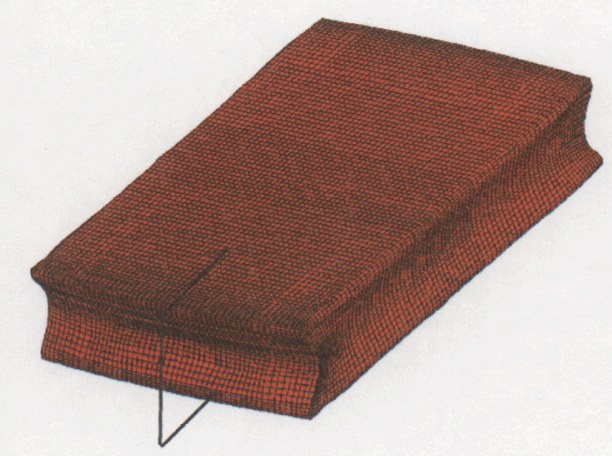

b) Simulation

Figure 1 Shape geometry at the end of $8^{\text {th }}$ pass for a) experiment, and b) simulation

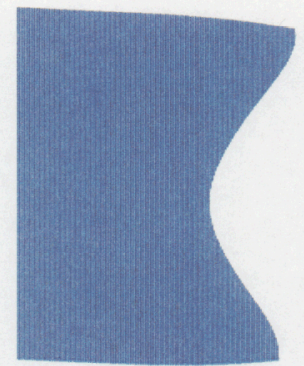

a) Experiment

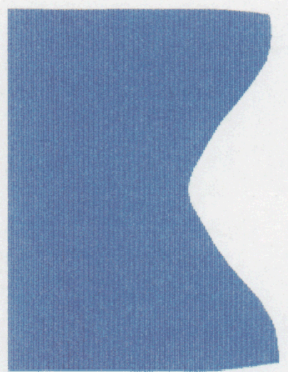

b) Simulation

Figure 2 Slab geometry at the centerline of the slab at the end of the $8^{\text {th }}$ pass for a) Experiment, and b) FEM simulation. 


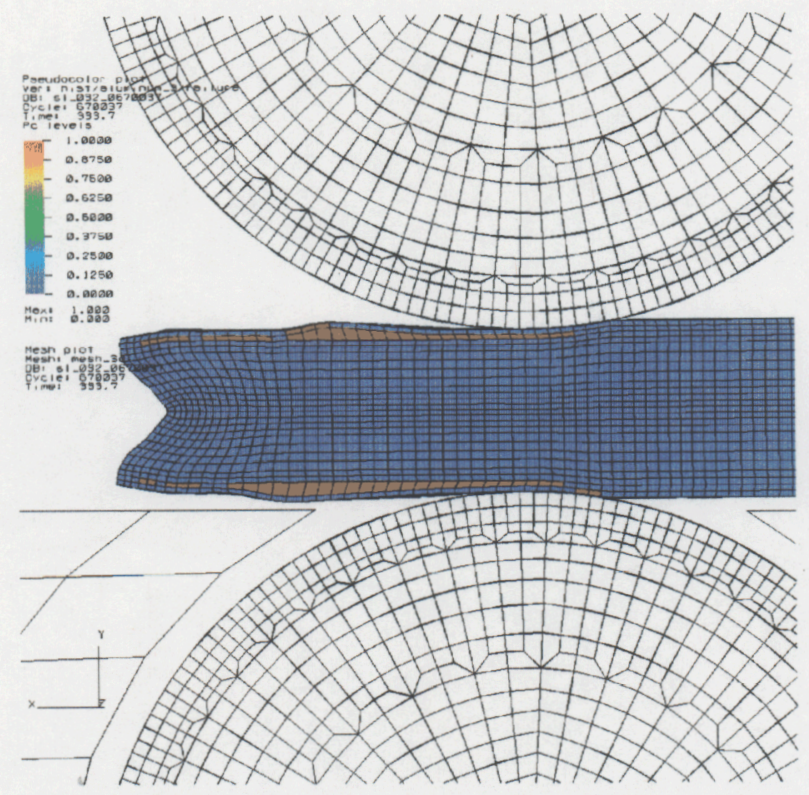

Figure 3 Facture plot at the center plane of the slab. Red color indicates fractured element.

\begin{abstract}
Alcoa Input
Protected CRADA Information

Quarterly Report - Alcoa Contract 74518, Development of A rolling Process Design Tool
\end{abstract}

From April 1, 2003 to June 30, 2003

- License agreement between LLNL and Alcoa for government software (ALE3D) transferred to industrial use has been initiated and signed.

- Additional Data analysis of lab rolled slabs (protected CRADA information) Alcoa's 3D Coordinate Machine recorded dimensional data of the three lab rolled slabs. The data was then imported to CAD machine to be converted into Abaqus FEM input deck. The first set of dimensional data was transferred in $1 \mathrm{Q}$ to LLNL personnel for simulation comparison. The additional two sets of data were transferred to LLNL in 2Q, 2003. LLNL plans to compare these experimental data with numerical results obtained from ALE3D.

- Note:

1. Alcoa proprietary data means the data was developed by Alcoa before this CRADA activity started 
2. Protected CRADA information means Alcoa data was produced in performance of this CRADA project. This data can not be released for 5 years

3. All data generated by LLNL under this CRADA project is restricted under the rules governed by "Protected CRADA Data" 
OMB Burden Disclosure Statement

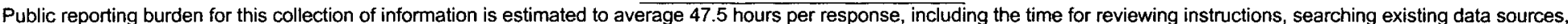

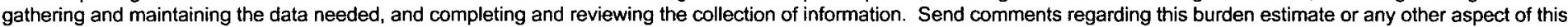

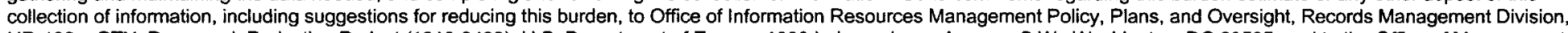

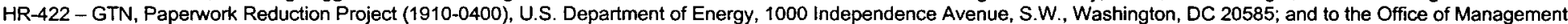
and Budget (OMB), Paperwork Reduction Project (1910-0400), Washington, DC 20503.

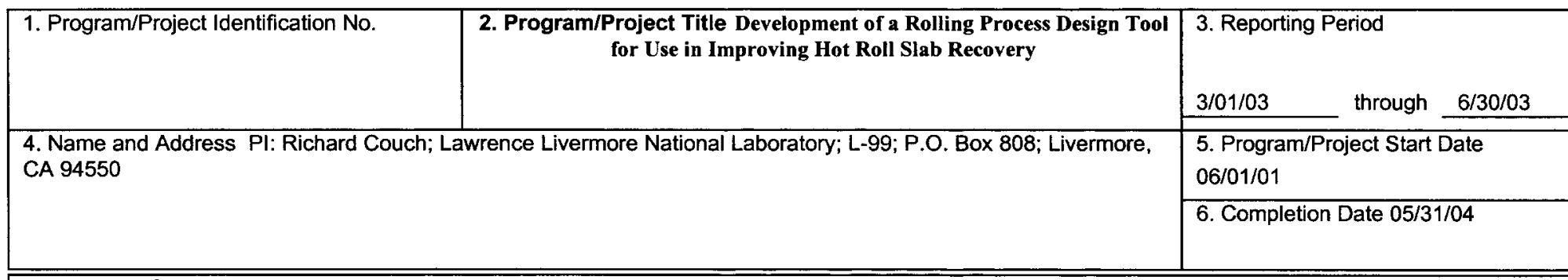

\section{Approach Changes}

$x$ None

8. Performance Variances, Accomplishments, or Problems

$x$ None

9. Open Items

$x$ None

10. Status Assessment and Forecast

$x$ No Deviation from Plan is Expected

11. Description of Attachments

$\mathrm{x}$ None 


\section{U.S. Department of Energy \\ Milestone Log}

Development of a Rolling Process Design Tool for Use in Improving Hot Roll Slab Recovery

\begin{tabular}{|c|c|c|c|}
\hline $\begin{array}{l}\text { Identification } \\
\text { Number }\end{array}$ & Description & $\begin{array}{c}\text { Planned Completion } \\
\text { Date }\end{array}$ & $\begin{array}{c}\text { Actual Completion } \\
\text { Date }\end{array}$ \\
\hline 1. & $\begin{array}{l}\text { Constitutive model } \\
\text { defined: PQ3 }\end{array}$ & $3 / 02$ & $3 / 02$ \\
\hline 2. & $\begin{array}{l}\text { Fracture model defined: } \\
\text { PQ5 }\end{array}$ & $9 / 02$ & $9 / 02$ \\
\hline 3. & $\begin{array}{l}\text { Friction model defined: } \\
\text { PQ3 }\end{array}$ & $3 / 02$ & $3 / 02$ \\
\hline 4. & $\begin{array}{l}\text { Finite element model } \\
\text { constructed: } \mathrm{PQ} 4\end{array}$ & $6 / 02$ & $6 / 02$ \\
\hline 5. & $\begin{array}{c}\text { Rolling data produced: } \\
\text { PQ6 }\end{array}$ & $12 / 02$ & $12 / 02$ \\
\hline 6. & $\begin{array}{l}\text { Initial code validation } \\
\text { studies completed: PQ8 }\end{array}$ & $6 / 03$ & $6 / 03$ \\
\hline 7. & $\begin{array}{l}\text { Validate models in a } \\
\text { production } \\
\text { configuration: PQ10 }\end{array}$ & $12 / 03$ & \\
\hline 8. & $\begin{array}{l}\text { Complete parameter } \\
\text { study: PQ12 }\end{array}$ & $6 / 04$ & \\
\hline
\end{tabular}

